\title{
VI Congress der deutschen Gesellschaft für Gynaekologie
}

\section{Der}

wird dieses Jahr

vom 5. bis 7. Juni in Wien tagen.

Die Sitzungen werden $\Lambda$ rormittags von 8-12 und Nachmittags von 1-3 in dem Hause der k. k. Gresellschaft der Ärzte in Wien IX, Frankgasse 8, abgehalten werden.

Anmeldungen zu Demonstration en und Vorträgen mögen bis 10. April an den ersten Vorsitzenden des Ausschusses der Gesellschaft geleitet werden.

Kranke, welche von Gesellschaftsmitgliedern vorgestellt werden sollen, können nach vorheriger Anmeldung in der Klinik des I. Vorsitzenden im k. k. allgemeinen Krankenhause untergebracht werden.

Auskünfte jeder Art ertheilt der I. Vorsitzende und die beiden Schriftfiihrer.

$\mathrm{Zu}$ reger Beteiligung ladet die Fachgenossen ein

Der Vorstand der deutschen Gesellschaft für Gynaekologie.

Chrobak, Wien IX. Fritsch, Bonn, Schatz, Rostock,

Frankgasse 6 (I. Vorsitzender). (Stellvertretender Vorsitzender). (Kassenführer).

v. Winckel, München. Schauta, Wien.

Pfarmenstiel, Breslau, Lihotzki, Wien,

Klosterstrasse I (I. Schriftfiihrer). Maria-Theresienstrasse 8 (II. Schriftfiihrer). 